\title{
POPULATION DENSITY OF SOME INSECT PESTS INFESTING GLOBE ARTICHOKE PLANTATIONS IN RELATION TO CERTAIN ECOLOGICAL FACTORS AT DAKAHALIA GOVERNORATE
}

Taha, M. A. ; Horia A. Abd-el Wahab ${ }^{2}$; Hanaa I. Mahmoud ${ }^{1}$ and Ghada EL S. Abd el hamed ${ }^{2}$

1. Science College, Al Azhar Univ., Cairo, Egypt

2. Plant Protection Research Institute, ARC, Dokki- Giza, Egypt

\begin{abstract}
Field experiments were conducted at Dakahlia Governorate during two successive seasons 2007/2008 and 2008/2009 to study the population density of some insect pests infesting globe artichoke plantations namely Capitophorus horni Born, Empoasca discipiens Poali, Autographa gamma Linn. and Spodoptera littoralis (Biosd). Also the effect of certain weather factors (daily mean temperatures and daily mean R.H.) and plant age were studied on the population dynamics of the various insect pests. The weather factors and plant age had insignificant effect on the population density of $C$. horni, E. discipiens, A. gamma and S. littoralis. Also, the relative humidity had shown significant effect on population density of the four insect pests during the two seasons 2007/2008 and 2008/2009. The percentage of explained variance was $92.5 \& 86.5$ during the two successive seasons, respectively.
\end{abstract}

\section{INTRODUCTION}

Globe artichoke (Cynara scolymus L.) belongs to family Asteraceae (Compositae) is becoming one of the most important vegetable crops grown for both local consumption and export (Mansour, 1983 and Tawfik, 1994). Throughout the growing season, globe artichoke plants are liable to infestation by phytophagous pests such as Capitophorus horni Born, Empoasca discipiens Poali, Spodoptera littoralis Biosd and Autographa gamma Linn., which considered the most common and important insect pests of globe artichoke plants. In heavy infestation, these pests are causing serious damage to plants, leading to great reduction in the yield (Schrameyer, 2002). Aphids play an important role as a vector of plant viruses and produce honeydew (Kasperovich, 2002). Therefore, the purpose of this work was to study the effect of plant age and certain weather factors on the population density of some insect pests infesting globe artichoke.

\section{MATERIALS AND METHODS}

The experiments were carried out in the farm of Agriculture Research Center at Baramoon, Dakahlia Governorate during two successive seasons 2007/ 2008 and 2008/2009. An Area (about feddan) ,divided into nine replicates, was planted with globe artichoke (Balady variety), on $1^{\text {st }}$ November and $2^{\text {nd }}$ October during the $1^{\text {st }}$ and $2^{\text {nd }}$ seasons, respectively. Every two weeks randomly samples of ten leaves from ten plants from each replicate were collected and put in paper bags and taken to the laboratory, 
where carefully examined by the aid of a stereoscopic-microscope for counting the insect pests. The whole area was free from any pesticides treatment. The artichoke aphid, Capitophorus horni Born. (nymphs and adults), Empoasca discipiens Poali (adults), Autographa gamma Linn. (immature stages and adults) and Spodoptera littoralis (Biosd) (immature stages and adults). were Counted and recorded at two weeks until the end of the season.

The records of meterological data, the daily mean of minimum, maximum temperatures and daily mean relative humidity, were obtained from the meteorological records of Central Laboratory for Agriculture climate, Agriculture Research Center in Dakahlia Governorate.

\section{Statistical analysis:}

To investigate effects of plant age, weather factors on the population dynamics of the insects, simple correlation and partial regression were carried out using MSTAT program.

\section{RESULTS AND DISCUSSION}

Population fluctuations studies on, the Capitophorus horni Born., Empoasca discipiens Poali, Autographa gamma Linn. and Spodoptera littoralis (Biosd.) were invistigated during the two seasons 2007/2008 and $2008 / 2009$.

\section{Season 2007/2008:}

The data illustrated in Fig. (1) showed that the infestation of artichoke aphid, $C$. horni was started at 30 days after sowing on $9^{\text {th }}$ December (334 individuals / 10 leaves) then it was increased sharply to reach its maximum (1941 individuals / 10 leaves) at 72 days after planting date on $6^{\text {th }}$ January. After that the insect population fluctuated and decreased gradually to reach moderate level ( 505 individuals $/ 10$ leaves) on $16^{\text {th }}$ March after 128 days from planting and fluctuated and increased to reach (1566 individuals/ 10 leaves) at $30^{\text {th }}$ March. Finally the insect population decreased sharply to reach a lower level (5 individuals/ 10 leaves) at 184 days after planting on $11^{\text {th }}$ May then the insect disappeared until the end of cultivation on $6^{\text {th }}$ July 2008. Meanwhile, data illustrated that the population of $C$. horni was obviously higher on young plants than the older one. Theses results were in agreement with Barbagallo (1974).

Data represented in Fig. (1) indicated that the infestation of the artichoke leaves with $E$. discipiens appeared after 30 days after planting on19 ${ }^{\text {th }}$ December 2007(11 individuals/ 10 leaves) then disappeared absolutely until 11 May 2008 (24 individuals/ 10 leaves) after 184 days from planting. After that increased sharply after 212 days on $8^{\text {th }}$ June and reached (146 individuals/ 10 leaves). Finally the insect population decreased gradually on $6^{\text {th }}$ July after 240 days planting date (38 individuals/ 10 leaves). These results indicated that high number of insects infested the older plants of artichoke than the younger ones.

Data explained in Fig. (1) The infestation of the leaves of globe artichoke with S. littoralis appeared at 170 days after cultivation on $27^{\text {th }}$ April (12 individuals/ 10 leaves). Then the population decreased until the end of 
cultivation on $6^{\text {th }}$ July 2008 after 240 days from planting date. These results also indicated that the older globe artichoke plants infested with $S$. littoralis than the younger plants. Theses results were in agreement with Rina and Paolo (1980).

Data showed in Fig. (1) illustrated that the infestation of globe artichoke leaves with Autographa gamma initiated after 156 days from planting on $13^{\text {th }}$ April 2008 (10 individuals/ 10 leaves). Then the population increased to become (18 individuals/ 10 leaves) after 170 days on $27^{\text {th }}$ April then the population deceased and then increased to reach (12 individuals/ 10 leaves) in the end of cultivation on $6^{\text {th }}$ July 2008 after 240 days from planting date. This means that older globe artichoke plants were infested by $A$. gamma more than younger ones. Theses results were in agreement with Rina and Paolo (1980).

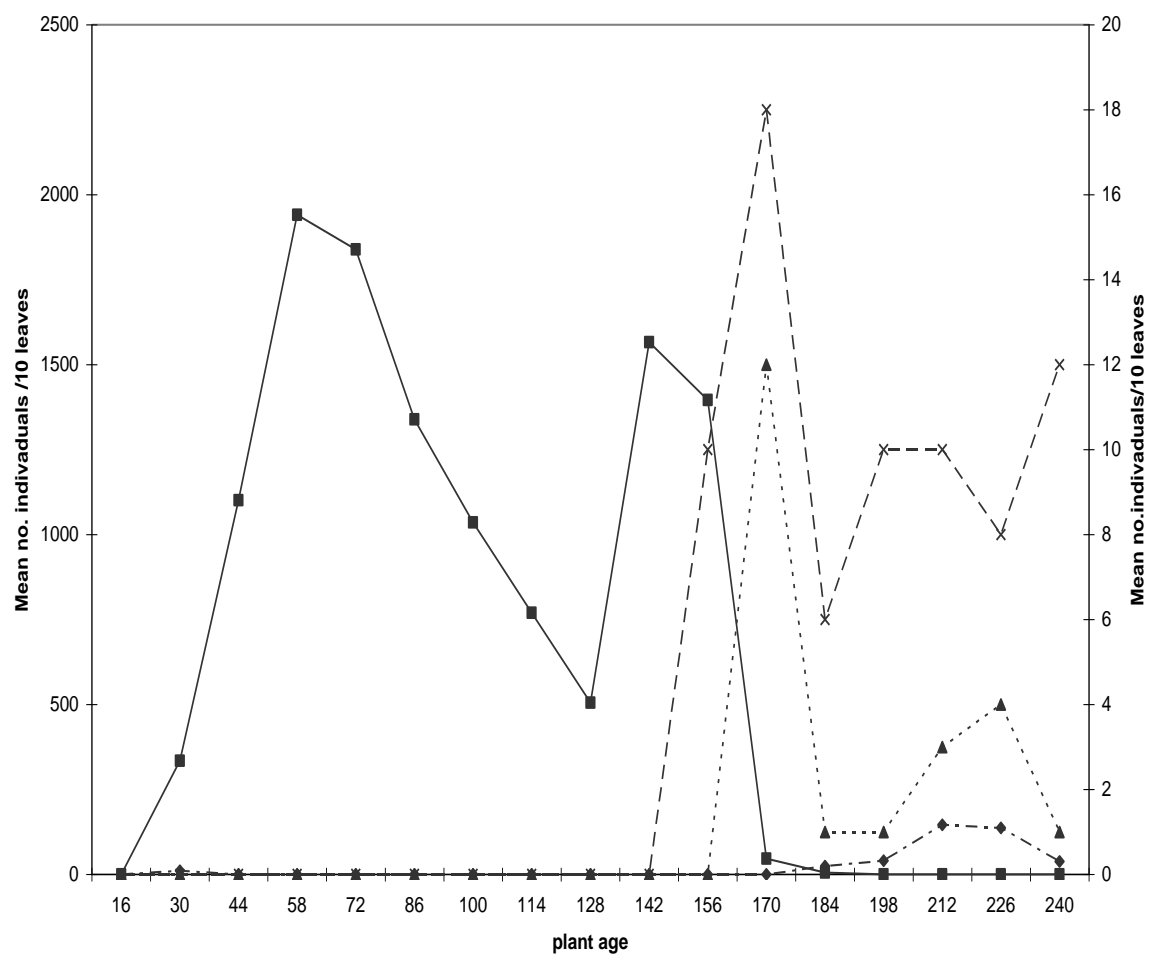

Fig (1): Population fluctuation of some insects infesting leaves of globe artichoke plant during 2007/ 2008 season in Dakahlia Governorate.

As shown in Table (1) the simple correlation "r" indicated insignificant correlation between the age of globe artichoke plants and the population of C. horni and $S$. littoralis on globe artichoke cultivar $(r=0.487$ and 0.429$)$, respectively, while there was significant correlation between the age of globe artichoke plants and the population of E. discipiens, and A. gamma $(r=0.509$ and 0.548$)$. The real effect of this factor which appears from the partial 
Taha, M. A. et al.

regression values on $C$. horni, E. discipiens $S$. littoralis and A. gamma population revealed significant effect ( b. reg. $=4.614,1.735,2.913$ ). respectively, during 2007/2008 season. Also, insignificant correlation was found between the insect populations and daily relative humidity $(r=0.206)$ during the season $2007 / 2008$ season. The partial regression analysis for the effect of weather factors on the populations, revealed that means of daily maximum and minimum temperatures had significant effect (b. reg. $=7.686 \& 1.795)$, respectively, during the season of $2007 / 2008$. Also, the means of daily relative humidity had significant effect (b. reg.=1.185). These results are in agreement with El- Khouly et al. (1998).

The obtained results revealed that the combined effect of the tested plant age and weather factors was significant on the insects population where the calculated "f" value was 7.60 .

The analysis of the variance revealed that the weather factors and the plant age are responsible for about $92.5 \%$ of the variability in the populations of the observed pests on the artichoke cultivar during 2007/2008 season.

Table (1): Effect of plant age and weather factors on the population fluctuations of some insect pests infesting globe artichoke cultivar during 2007/2008 season at Dakahlia Governorate.

\begin{tabular}{|c|c|c|c|c|c|c|c|c|c|c|}
\hline & \multirow[t]{2}{*}{ Factors } & \multicolumn{3}{|c|}{$\begin{array}{c}\text { Simple correlation } \\
\text { and regression } \\
\text { values }\end{array}$} & \multicolumn{3}{|c|}{$\begin{array}{c}\text { Partial regression } \\
\text { values }\end{array}$} & \multicolumn{2}{|c|}{$\begin{array}{c}\text { Analysis of } \\
\text { variance }\end{array}$} & \multirow[t]{2}{*}{$\begin{array}{c}\text { E.V. } \\
\%\end{array}$} \\
\hline & & $\mathbf{r}$ & b & S.E. & b. reg. & S.E. & $p$ & $\mathbf{F}$ & $\mathbf{P}$ & \\
\hline \multirow{4}{*}{$\begin{array}{l}\text { Insect } \\
\text { pests }\end{array}$} & Capiyophorus horni & 0.487 & 4.532 & 2.044 & 4.614 & 2.081 & 0.01 & \multirow{7}{*}{7.60} & \multirow{7}{*}{0.004} & \multirow{7}{*}{92.5} \\
\hline & Empoasca discipiens & 0.509 & 2.637 & 3.079 & 1.735 & 2.025 & 0.03 & & & \\
\hline & Spodoptera littoralis & 0.429 & 6.877 & 4.959 & 2.913 & 2.101 & 0.03 & & & \\
\hline & Autographa gamma & 0.548 & 5.913 & 3.471 & 4.886 & 2.868 & 0.01 & & & \\
\hline \multirow{3}{*}{$\begin{array}{l}\text { Weather } \\
\text { factors }\end{array}$} & Daily mean max. temp. & 0.327 & 6.253 & 4.609 & 7.686 & 5.666 & 0.01 & & & \\
\hline & Daily mean min. temp. & 0.481 & 2.173 & 7.366 & 1.795 & 6.084 & 0.03 & & & \\
\hline & Daily mean R.H. & 0.206 & 3.196 & 2.352 & 1.185 & 3.798 & 0.01 & & & \\
\hline
\end{tabular}

\section{Season 2008/2009:}

The data illustrated in Fig. (2) showed that globe artichoke leaves infested with $C$. horni was very high and started after 47 days of planting on $18^{\text {th }}$ November 2008 (101 individuals/ 10 leaves). Then the population increased to reach sharply (738 individuals/ 10 leaves) after 187 days of planting on $7^{\text {th }}$ April 2009. After that the insect population decreased to reach ( 1 individual/ 10 leaves) at the end of cultivation after 257 days of planting on $16^{\text {th }}$ June 2009. Theses results indicated that $C$. horni preferred the younger globe artichoke plants than the older ones. These results are in agreement with Barbagallo (1974) and Maisonneuve et al. (2003).

Data in Fig. (2) showed that the infestation of globe artichoke leaves with E. discipiens started on $24^{\text {th }}$ March 2009 after 173 days of planting date (5 individuals/ 10 leaves). Then, the population increased rapidly to reach (15 individuals/10 leaves) after 187 days from cultivation on $7^{\text {th }}$ April and finally 
the population decreased. Theses results indicated that $E$. discipiens preferred the older globe artichoke plants than the younger ones.

The results showed in Fig. (2) that infestation of the globe artichoke leaves with $S$. littoralis which started in $21^{\text {st }}$ April 2009 after 201 days and then disappeared but after that appeared again and reached (7 individuals/ 10 leaves) in the end of cultivation after 257 days of planting date on $16^{\text {th }}$ June. The results showed that $S$. littoralis preferred the older globe artichoke plants than the younger ones. These results are in agreement with Rina and Paolo (1980).

Data in Fig. (2) indicated that globe artichoke leaves infested with $A$. gamma after 187 days of planting date on $7^{\text {th }}$ April 2009 (3 individuals/ 10 leaves). Then, the population increased rapidly to reach (46 individuals/ 10 leaves) after 215 days of sowing on $5^{\text {th }}$ May. After that the population fluctuated and decreased and finally the population increased again to reach (50 individuals/ 10 leaves) after 257 days on $16^{\text {th }}$ June. These results revealed that $A$. gamma infest the older globe artichoke plants than the younger plants. These results are in agreement with Rina and Paolo (1980).

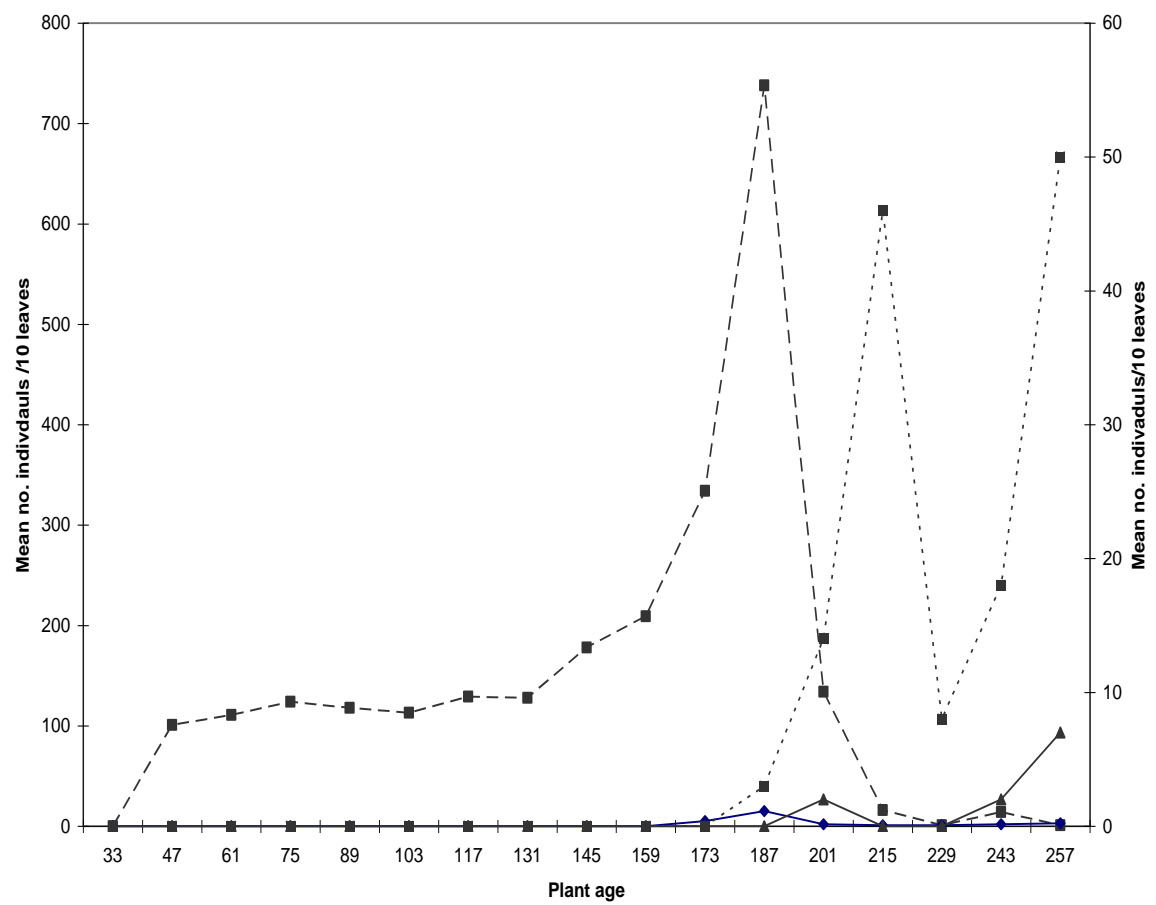

Fig. (2): Population fluctuation of some insects infesting leaves of globe artichoke plant during 2008/ 2009 season in Dakahlia Governorate.

As showen in Table (2) the simple correlation " $r$ " indicated significant correlation between the age of globe artichoke plants and the population of C. horni, S. littoralis and A. gamma on globe artichoke cultivar $(r=0.540$, 
Taha, M. A. et al.

0.852 and 0.732 ). The real effect of this factor which appears from the partial regression values on $C$. horni, E. discipiens, S. littoralis and A. gamma population revealed significant effect (b. reg.= 6.591, 6.982, 2.731 and 2.301), respectively, during the season $2008 / 2009$ season.

In Table (2)The results indicated insignificant correlation between the populations of insects and mean daily maximum, minimum temperatures and daily mean of relative humidity $(r=0.038,0.198$ and 0.183$)$, respectively, during 2008/2009 season. The partial regression analysis for the effect of weather factors on the populations revealed that means of daily maximum, minimum temperatures and daily relative humidity had significant effect (b. reg.= 1.819\& 1.409 ), respectively, during the season of 2008/2009, as shown in table (2). Also, the means of daily relative humidity had significant effect (b. reg.= 9.867). These results are in agreement with El- Khouly et al. 1998 ; CAB, (2003) and Maisonneuve et al (2003).

The obtained results revealed that the combined effect of the tested plant age and weather factors was $86.5 \%$ on the insects population where the calculated " $f$ " value was 3.82 .

The analysis of the variance revealed that the weather factors and the plant age are responsible for about $86.5 \%$ of the variability in the populations of the observed pests on the artichoke cultivar during 2008/2009 season.

Table 2: Effect of plant age and weather factors on the population fluctuations of some insect pests infesting globe artichoke cultivar during 2008/2009 season at Dakahlia Governorate.

\begin{tabular}{|c|c|c|c|c|c|c|c|c|c|c|}
\hline \multirow{2}{*}{\multicolumn{2}{|c|}{ Factors }} & \multicolumn{3}{|c|}{$\begin{array}{c}\text { Simple correlation } \\
\text { and regression } \\
\text { values }\end{array}$} & \multicolumn{3}{|c|}{$\begin{array}{c}\text { Partial regession } \\
\text { values }\end{array}$} & \multicolumn{2}{|c|}{$\begin{array}{c}\text { Analysis } \\
\text { of } \\
\text { variance }\end{array}$} & \multirow[t]{2}{*}{ E.V.\% } \\
\hline & & $\mathbf{r}$ & b & S.E. & b. reg. & S.E. & $p$ & $\mathbf{F}$ & $\mathbf{P}$ & \\
\hline \multirow{4}{*}{ pests } & Capiyophorus horni & 0.044 & 2.649 & 2.891 & 6.591 & 7.191 & 0.01 & \multirow{7}{*}{3.82} & \multirow{7}{*}{0.03} & \multirow{7}{*}{86.5} \\
\hline & Empoasca discipiens & 0.852 & 1.333 & 1.261 & 6.982 & 6.606 & 0.03 & & & \\
\hline & Spodoptera littoralis & 0.258 & 1.093 & 1.089 & 2.731 & 2.721 & 0.01 & & & \\
\hline & Autographa gamma & 0.332 & 1.019 & 1.437 & 2.301 & 3.243 & 0.03 & & & \\
\hline \multirow{3}{*}{$\begin{array}{l}\text { Weather } \\
\text { factors }\end{array}$} & Daily mean max. temp. & 0.038 & 1.792 & 9.982 & 1.819 & 1.013 & 0.01 & & & \\
\hline & Daily mean min. temp. & 0.198 & 2.185 & 1.309 & 1.409 & 8.443 & 0.01 & & & \\
\hline & Daily mean R.H. & 0.183 & 4.568 & 2.274 & 9.867 & 4.912 & 0.01 & & & \\
\hline
\end{tabular}

\section{REFERENCES}

Barbagallo, S. (1974): Observations on the aphids (Homoptera, Aphidoidea) of artichoke (Cynara scolymus L.). Bollettino del Laboratorio di Entomologia Agraria' Filippo Silvestri' Portici. 31, 197- 252.

CAB, Crop Protection Compendium (2003): global module. Commonwealth Agricultural Bureau International, Wallingford, UK.

El-Khouly, A.S.; E.M.E. Khalafalla; M.M. Metwally, H.M. Helal and A.B. Mezaien (1998). Seasonal abundance and population dynamics of certain sucking insects on Soya bean in Kafr-El-sheikh Governorate, Egypt. J. Agric. Res., 76(1): 141-151. 
Kasperovich, E. (2002): Application of baciturine in Aphis gossypii and Tetranychus urticae number limitation in the protected ground. Scientific Conference dedicated to the $90^{\text {th }}$ anniversary of the birth of the corresponding member of the AS RB AL Samersov Minsk Prilukii, 177- 180.

Maisonneuve, J. C.; N. Hugon and F. Lolivier (2003): Biological control with Chrysoperla lucasina against Aphis fabae on artichoke in Brittany (France). Bull. OILB/ SROP. 26:3, 149-153.

Mansour, A.S. (1983): Effect of some growth regulators on some physiological characters and the yield of globe artichoke. M. Sc. Thesis, Fac. Agric. Cairo Univ. 88pp.

Rina,I and P. Paolo (1980): Observations on catches of Lepidoptera in a cultivated field of Polignano (Bari). Entomologica. 16, 143- 182.

Schrameyer, K. (2002): Pests of artichokes. Gemuse Munchen. 38:3, 16-18.

Tawfik, A.M. (1994): Morphological and physiological studies on globe artichoke. Ph.D. Thesis, Fac. Agric. Cairo Univ. 150 pp.

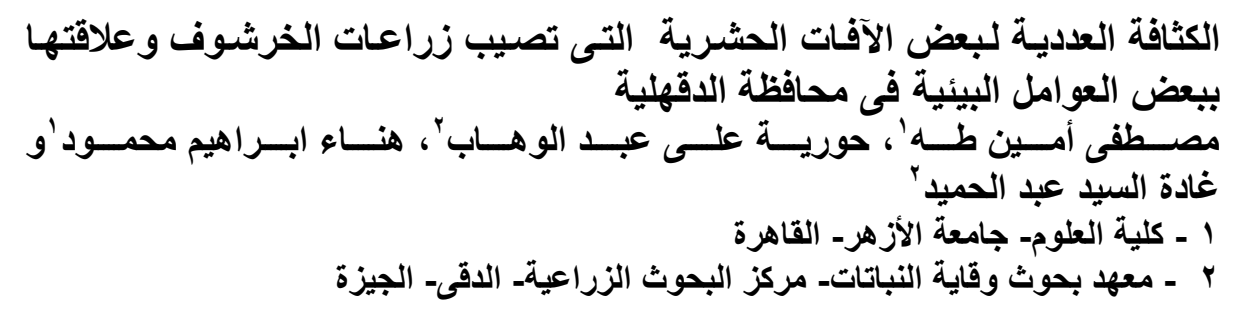

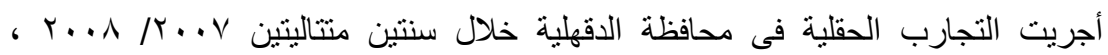

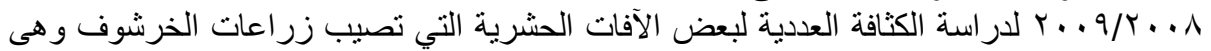

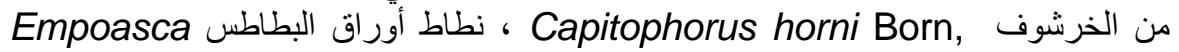
discipiens Poali

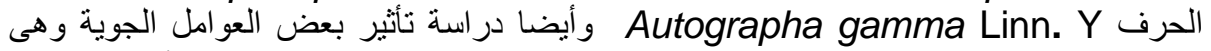
درجة الحر ارة الصغرى والكبرى والرطوبة النسبية وعمر النبات على التغير لتعداد الآفات الحشرية

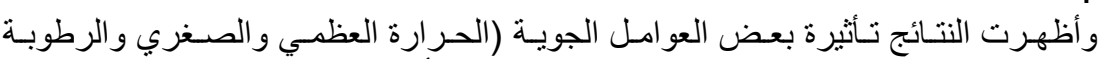

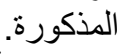

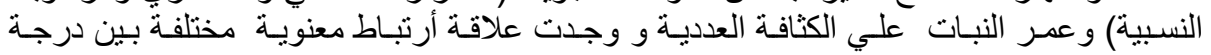

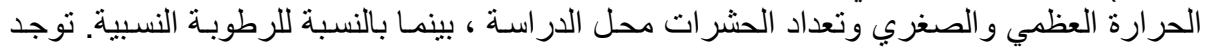

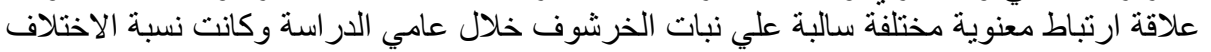

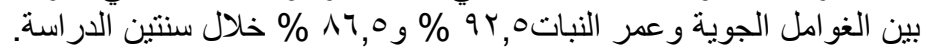

كلية الزراعة - جامعة المنصورة

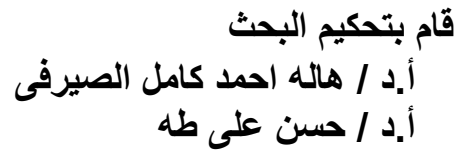

